\section{THE ETIOLOGY AND TREATMENT OF ENURESIS *}

\author{
JOSEPH I. GROVER, M.D.
}

Assistant in Pediatrics, Medical School of Harvard University; Junior Assistant Physician, Children's Hospital

BOSTON

About 200 cases of bedwetting were studied for a period of more than seven months. Most of the patients of less than 4 years of age and a few older ones were not used because they were not sufficiently developed mentally to be willing to undergo privations as an end to their cure. Children more than 12 years old were not seen. The treatment was not outlined to patients not living with their parents, who would not make the necessary sacrifices, nor to patients brought in by neighbors. Children with cord lesions or other organic nervous diseases, diabetics, and those with marked mental disorders were considered as outside the scope of this study.

Boys comprised 62 per cent. of the cases. Blond children predominated. There was a history of enuresis in the immediate family in 56 per cent., including grandparents, aunts and uncles.

In 59 per cent. of the cases, the wetting took place only at night, and 38 per cent. wet both day and night. Less than 3 per cent. were day wetters exclusively. Incontinence of feces was encountered twice. In 68 per cent. the wetting occurred every night. The remainder wet less frequently. Seventy-nine per cent. had always wet the bed from babyhood; 20 per cent. began later in life after a normal period. Of the latter, four started with scarlet fever, one with chorea, and one after a fall from a window.

\section{CONDITIONS ACCOMPANYING ENURESIS}

The etiology, as usually considered, varies from malnutrition to a concentrated urine and even adenoids. As to adenoids, 36 per cent. of my patients had had them removed without apparent relief. In two cases the wetting was definitely worse after the operation. Fifty-one per cent. of the boys had previously been circumcised, and were, nevertheless, bed-wetters. Only three boys and one girl had adhesions of the prepuce. The adhesions were not broken up, and the cases in question numbered among the easily relieved in spite of the adhesions. Acidity, alkalinity, and high or low specific gravity of the urine were all held as of little consequence, and were never allowed to influence the treatment. Pus in the urine was always considered an evidence of inflammation, often very mild, and was cleared up before the enuresis treatment was instituted.

There was a definite history of pinworms in 20 per cent. of the cases. Besides these, there was a definite history of pinworms in either a parent or brother or sister in 32 per cent. I believe a much higher percentage among the enuresis patients would be found to have worms, had they all been given an appropriate treatment to bring the worms to light. Whether the incidence of pinworms in cases of enuresis is of greater proportion than in the ordinary run of cases, I am not prepared to say, but I am of the opinion that the proportion is greater, and that the pinworms may often be of at least secondary impor-

* From the Medical Outpatient Department of the Children's Hospital.

* Read before the Section on Diseases of Children at the Sixty-Ninth Annual Session of the American Medical Association. Chicago. June, 1918. tance in the etiology of enuresis. The worms were prevented from accumulating by the giving of calomel and santonin.

There were many accompanying conditions present, among the more frequent being pinworms in thirtyfour cases, pyelitis in eleven, tuberculosis in five, chorea in four, orthostatic albuminuria in four, adherent prepuce in four, and thirteen other conditions, such as one would expect to meet in any clinic. Only two patients were feebleminded, and four had some external genital abnormality. Most of the patients in the series were underweight, only one being definitely overweight.

About half the patients in this series had been previously treated by various other methods, many having been tried along two, three and even four lines. Twenty-six had been circumcised without any benefit, two becoming a trifle worse. Forty-nine had had their tonsils or adenoids or both removed to improve their condition. Twenty-four had had a more or less thorough "atropin treatment." Sixteen had received some form of alkali for an acid urine.

\section{ETIOLOGY}

Enuresis is probably never a disease entity, but simply a symptom or evidence of an underlying cause, namely a neuromuscular fatigue. This fatigue is not localized to the genito-urinary nerves and muscles, but is general. It is not an acute fatigue or exhaustion, but a chronic one. Enuresis patients are alike in many manifestations. They are all exceedingly active and nervous. When night comes, they are dead tired and sleep so soundly that it is almost impossible to wake them. Some slept so profoundly that it was impossible at $10 \mathrm{p.} \mathrm{m}$. to awake them sufficiently to urinate, and when they were put back to bed they wet within five minutes. The children were never thoroughly rested because their period of sleep was never long enough to overcome the fatigue and strain of the long, active day. I believe it is due to such a neuromuscular fatigue that some children stutter and others have habit spasms. In bedwetting, control is lost over a certain group of muscles, but the general fatigue and loss of tone is behind it all.

Mental strain is often also a factor. Many of my patients attended parochial school that required almost seven consecutive hours of work. Then they were required to spend two or three hours doing home lessons at night. Such mental strain creates fatigue. If there is enuresis in such a child, it usually cannot be controlled until school is abandoned for a while and the general body tone revived.

Diet is an equally important factor in producing the general fatigue. The diet in over 95 per cent. of my cases was very poor. The patients were getting plenty of food, but not of the right kind or at the right time. More than half were getting baked beans for two meals in the week. Candy, cake, ice cream, syrup, molasses, cocoa, coffee, tea, apples, bananas, frankforts and pickled herring were daily offenders. Indigestion was uncommon, but such articles of diet and the food eaten between meals kept the gastro-intestinal system under a constant strain, and added appreciably to the general body fatigue. Adenoids, adherent prepuce, highly acid urine and irritation from worms may also add their mite to the creation of a general fatigue. As heredity plays an important part, the fatigue may be easily explained as a congenital lack of general systemic tone. 
Not only is there an underlying cause in entresis, namely, general neuromuscular fatigue, but there is another and most important factor-habit. After the underlying cause has been removed, the habit of bedwetting may still remain. The treatment for the habit is very different from the treatment for the underlying cause, and is often more difficult to overcome. Many of the patients, when they present themselves for treatment, have only the habit remaining. Regularity in urination may in itself cure many of these. I imagine it is in this sort of case that suggestion, electricity, spinal douches, and surgical methods usually meet with good results in many hands.

May I compare the cause and habit in enuresis to the cause and habit in whooping cough and also in chorea? After the infection in whooping cough has long passed, the characteristic spasmodic cough often persists for months. It is simply an uncontrollable muscular habit, due to a cause no longer present. After the infection in chorea has passed, there persists again an incontrollable habit, dependent on, but entirely different from the original cause, namely, the infection.

The size of the bladder must also be considered. When enuresis has continued from babyhood, the bladder, continually emptying itself, is probably never distended to more than a capacity of from one to three ounces. This physical condition must be treated by gradually lengthening the periods between urinations.

\section{TREATMENT}

The treatment for enuresis in this series was planned absolutely along dietary and hygienic lines, with emphasis laid especially on more sleep and rest hours. No drugs, operations or mechanical means were employed. Printed directions were supplied to each mother and every minute detail explained.

All food was forbidden between meals, even milk and bread and butter. The diet list included milk, butter, eggs, meat, fish, breadstuffs, cooked cereals, macaroni, vegetables, orange, stewed fruits and simple, unsweetened desserts. It excluded soups, coffee, tea, cocoa, sweet and salty and highly seasoned food, ice cream, candy, pastry, cake, jellies, jams, etc., condiments, bananas and raw apples. Meat, eggs and vegetables were forbidden for supper, simply to make it easy for the digestive system at night.

The child was required to be in bed by $7 \mathrm{p}$. $\mathrm{m}$. If it was a very nervous child, school was prohibited temporarily, and a nap required at noon. No play was allowed after 4 p. $m$. The child was to be entertained by books or toys in a chair. Moving picture shows, music lessons and evening home lessons were prohibited.

The habit element was treated in the usual way. No fluids were allowed after $4 \mathrm{p}$. $\mathrm{m}$. There were regular hours for urination at night, namely, $7 \mathrm{p} . \mathrm{m}$. on going to bed, 10 p. m., and not again until $6 \mathrm{a} . \mathrm{m}$. Many children could not go eight hours because their bladders could not distend to hold more than two or three ounces. These were made to urinate also at 2 a. $m$. After a few weeks, the 2 a. m. urination was omitted. Punctuality was considered of prime importance; 7 p. m. meant 7 p. m., not 7:05 p. m. A regular habit for the time of urination means a great deal.

The day wetters were made to urinate at regular, stated times, anywhere from every three hours during the day down to every twenty minutes. The interval was gradually lengthened until a satisfactory regimen was reached.
It takes courage on the mother's part to carry out every detail of the treatment, because, unless the child is anxious to overcome his condition, she will have to watch him every minute in order that he does not eat between meals or take forbidden food, and to see that after $4 \mathrm{p} . \mathrm{m}$. he is quiet and drinks nothing. For this reason, the older the child, the more successful the treatment. At the first visit, much time was spent in explaining the details to the mother, and the reasons for them. At each subsequent visit the details were investigated by cross-examination, and the faults corrected. Rewards were offered, not for not wetting the bed, because the children do not know when they do that, but for following directions and refraining from the temptation of food and drink.

Nineteen per cent. of 131 cases did not wet the bed on any occasion after their first visit for instruction. Another 23 per cent. did not wet once after the first few weeks or months, not wetting for at least one month previous to May 1. An additional 31 per cent. were relieved to the extent that they never wet more than once a week. Thirteen and one half per cent. were partially relieved. Sixteen patients, or 12 per cent., were not relieved at all. When a combination of day and night wetting existed, the day wetting usually stopped first. This was because the child could purposely wait until the appointed time for urination. Both cases of incontinence of feces cleared up in less than a month.

After the child has been successfully wakened at $10 \mathrm{p} . \mathrm{m}$. and $6 \mathrm{a} . \mathrm{m}$. without wetting the bed for a few weeks, he usually wakes himself at those hours, but he should not be trusted to awake himself for fear of his oversleeping and thus breaking the "dry habit." This makes it easier to wet the next time. It may take many months of treatment to tone the body to such a degree that the enuresis habit will never recur under any conditions. After an apparent cure, an intercurrent cold or an upsetting of digestion will cause the bedwetting to begin again. This is probably due to a return of the general fatigue resulting from the infection or other disturbance.

In the treatment of enuresis, many of the other coexisting disorders were markedly improved. A habit spasm in one case and night terrors in two cases soon disappeared. Stuttering in another was greatly relieved. Attacks of petit mal were reduced 75 per cent. in one boy. The usual nervousness and irritability decreased so much that almost every parent remarked it without a hint. Almost every child gained weight. There was very often an initial loss of weight due to the fact that on the simple diet many of the children would not eat the plain food.

Many writers have described subacute inflammations of the urinary tract as either causes or accompanying conditions in many enuresis cases. It is a matter of common knowledge that mild cystitis and pyelitis are usually secondary conditions, flaring up when the patient is run down or diseased. It may be that the general body fatigue is responsible for the continuance of both the inflammation and the enuresis. On the same theory, atropin, strychnin and thyroid may act as a nerve or muscle tonic. It is usually conceded that the drugs have little effect unless used in conjunction with some hygienic treatment.

As this work was done on outpatients by themselves in their own homes, a perfect result could not reasonably be expected. The nature of the directions are such that the mother may repeat the whole treatment, after 
a discouragement, without consulting the physician. The purpose of this paper is to show the effect of a simple, regular diet and plenty of rest and little excitement on the underlying cause of enuresis, which is general neuromuscular fatigue. The wetting habit is secondary, and must be treated by limiting fluids and establishing regular hours for micturition.

272 Newbury Street.

\section{ABSTRACT OF DISCUSSION}

Dr. Harry Lowenburg, Philadelphia: I have never felt that I cured a case of enuresis. I have had them get well, but I have always thought I had little to do with it. I remember one family in which there were three children with this condition. The father paid me quite a fee for trying to cure this condition, and $I$ have felt conscience stricken ever since. The children eventually got well, but I do not believe I had anything to do with it. The doctor said he found underlying nervous fatigue. I believe that is true. The treatment for this is difficult, because we cannot remove the children from their own homes. To illustrate: A child was brought to me about four weeks ago. The mother said she could do nothing with the child; that it sat around all day and cried. The child cried in my office, and the mother said, "You stop crying; the doctor has a policeman in the house." I promptly told the mother she ought to commit suicide, that there was nothing I could do for the child unless the cause was removed. It is difficult to treat these cases from the fact that almost all of these parents are neurotic. The next case I get I am going to send to Boston to Dr. Grover.

Dr. H. M. McClanahan, Omaha: I have been disappointed often when children have been operated on for circumcision, without any result so far as the enuresis was concerned. I appreciate what Dr. Grover said in regard to diet. In children 8 to 12 years of age, the bladder is too small and will not hold a sufficient amount of urine to carry the child over the night. With the cooperation of the roentgenologist, we have somc data along this line. We must get the confidence of the child and persuade it to hold the urine as long as possible during the day so as to develop the bladder. This can be done. Boys may be instructed to stop the act of urinating several times in order to develop certain muscles. Another point is to have the patient make certain to empty the bladder. Older children should be instructed to drink very little fluid, say, after 5 o'clock.

Dr. M. L. Turner, Des Moines, Iowa: My experience has been somewhat different from Dr. Grover's. I read some place that enuresis was due to a lack of development of the nerve center that controls the bladder, and I have worked on that theory. Take a child 8,10 or 12 years of age, and make an impression on it in some way and it will stop bed-wetting within twenty-four hours. I have had a number of cases of that type. I think I can say that I have cured these patientsor at any rate the enuresis has stopped-in 75 per cent. of the cases. One of the first things $I$ do is to stop the drinking of fluid after 4 o'clock in the day, and have the mother impress on the child that it is keeping the fluid from the child to keep it from bed-wetting. Where the mother will cooperate we usually get good results. I have used medicine in some cases at 4,6 and 8 in the evening-usually tincture of nux vomica-and tell the mother to impress on the child that he is taking it to keep from wetting the bed. When the child has been impressed with this fact he ceases to wet the bed. One little girl came to the dispensary for treatment. The mother said the child would wet the bed within half an hour after going to bed, evidencing the fact that the center loses control before the bladder is full. I said to this girl, "You will soon be a young lady, and will want to have gentlemen call on you. Is your mother going to have to tell you that you cannot have callers because you wet the bed?" She went home and never wet the bed again. In another case the child was told she would have to have an operation if she did not stop wetting the bed. She went home and never wet the bed again.

Dr. Franklin N. Rogers, Manchester, N. H.: I am disappointed that there is not something more than the rule of rest that can be laid down for these little patients suffering with enuresis. It is discouraging not to be able to give these patients immediate relief. The point which impressed me most in Dr. Grover's paper is his emphasis on rest in the treatment of this condition. We all know rest is essential to children. The daylight saving plan which is now in operation has, without doubt, shortened the period of rest for children. It is hard to get a child to go to bed at the usual hour because it is so light. I agree also that there is a great deal of nervous irritability in these children-often due to family living conditions. A great deal can be done by the family for a child suffering with enuresis by enforcing the rules laid down by the doctor.

Dr. Joseph I. Grover, Boston: About a week before I left Boston I saw a boy, 11 years old, who wet the bed several times every night, and had done it ever since he was born. I explained everything to the boy in this case-he was educated and old enough to understand. Every day for the next eight days he was dry for the first time in his life. He passed his water at 10 o'clock at night and not again until 6 in the morning. In treating children by diet and rest, the child's general condition becomes improved. It seems that by treating enuresis children in general, with a good diet and rest, you can kill two birds with one stone.

\section{THE EFFECTS OF HIGH EXPLOSIVES ON THE EAR *}

\section{J. GORDON WILSON, M.B. CHICAGO}

The large number of men incapacitated for military service on account of deafness due to the concussion from high explosive shells is engaging the attention of military authorities in all the armies in this war. The number of men who will return to civil life with seriously impaired hearing demands the attention of otologists. I have chosen this subject for consideration, not only because it is urgent, but also because I have had considerable opportunity to observe such results in warfare and in addition have studied in a very modified degree corresponding effects in the laboratory. It shall be my endeavor to describe my observations and the results of my investigations rather than to attempt to offer any explanation or form any hypothesis.

The otologic cases resulting from the bursting of a shell are divided into two groups:

1. Those in which a piece of the shell has struck the ear. The trauma may have been limited to the external canal or to the mastoid, or may have involved the middle and internal ear. Injuries to the external canal or mastoid cause total or partial deafness on that side and at the same time some loss of hearing at least temporarily in the other ear. In addition, we have the results of the suppuration and contractures of the external meatus so apt to follow. Injuries involving the middle and internal ear are usually immediately fatal from associated injury to the brain, and those who survive are totally deaf in that ear.

2. Those in which the damage has come from the explosion without any fragment of the shell striking the ear or its immediate neighborhood. In some there has been no objective signs of any trauma, in others some fragments may have caused a trauma in a part remote from the temporal bone. It is with this second division that this paper is concerned. It includes a large number of cases in which the diagnosis is fre* Read before the Section on Laryngology, Otology and Rhinology
at the Sixty-Ninth Session of the American Medical Association, at the Sixty-Ninth 